\title{
NMR elucidation of nonproductive binding sites of lignin models with carbohydrate-binding module of cellobiohydrolase I
}

\author{
Yuki Tokunaga ${ }^{1}$, Takashi Nagata² ${ }^{2}$ Keiko Kondo², Masato Katahira ${ }^{2}$ and Takashi Watanabe ${ }^{1 *}$ (1)
}

\begin{abstract}
Background: Highly efficient enzymatic saccharification of pretreated lignocellulose is a key step in achieving lignocellulosic biorefinery. Cellobiohydrolase I (Cel7A) secreted by Trichoderma reesei is an industrially used cellulase that possesses carbohydrate-binding module 1 (TrCBM1) at the C-terminal domain. The nonproductive binding of $\operatorname{TrCBM1}$ to lignin significantly decreases the enzymatic saccharification efficiency and increases the cost of biomass conversion because of the additionally required enzymes. Understanding the interaction mechanism between lignin and $\operatorname{TrCBM1}$ is essential for realizing a cost-effective biofuel production; however, the binding sites in lignin have not been clearly elucidated.
\end{abstract}

Results: Three types of ${ }^{13} \mathrm{C}$-labeled $\beta$-O-4 lignin oligomer models were synthesized and characterized. The $2 \mathrm{D}^{1} \mathrm{H}-{ }^{13} \mathrm{C}$ heteronuclear single-quantum correlation (HSQC) spectra of the ${ }^{13} \mathrm{C}$-labeled lignin models confirmed that the three types of the ${ }^{13} \mathrm{C}$ labels were correctly incorporated in the (1) aromatic rings and $\beta$ positions, (2) a positions, and (3) methoxy groups, respectively. The TrCBM1-binding sites in lignin were analyzed by observing NMR chemical shift perturbations (CSPS) using the synthetic ${ }^{13} \mathrm{C}$-labeled $\beta$-O-4 lignin oligomer models. Obvious CSPs were observed in signals from the aromatic regions in oligomers bound to $\operatorname{TrCBM1}$, whereas perturbations in the signals from aliphatic regions and methoxy groups were insignificant. These findings indicated that hydrophobic interactions and $\pi-\pi$ stacking were dominating factors in nonproductive binding. The synthetic lignin models have two configurations whose terminal units were differently aligned and donated $C^{(I)}$ and $C^{(I)}$. The $C^{(I)}$ ring showed remarkable perturbation compared with the $\mathrm{C}^{(I)}$, which indicated that the binding of $\operatorname{TrCBM1}$ was markedly affected by the configuration of the lignin models. The long-chain lignin models (degree of polymerization (DP) 4.16-4.70) clearly bound to $\operatorname{TrCBM1.}$ The interactions of $\operatorname{TrCBM} 1$ with the short-chain lignin models (DP 2.64-3.12) were insignificant, indicating that a DP greater than 4 was necessary for TrCBM1 binding.

Conclusion: The CSP analysis using ${ }^{13} \mathrm{C}$-labeled $\beta$-O-4 lignin oligomer models enabled the identification of the $\operatorname{TrCBM} 1$ binding sites in lignins at the atomic level. This specific interaction analysis will provide insights for new molecular designs of cellulase having a controlled affinity to cellulose and lignin for a cost-effective biorefinery process.

*Correspondence: twatanab@rish.kyoto-u.ac.jp

${ }^{1}$ Research Institute for Sustainable Humanosphere (RISH), Kyoto University, Uji, Kyoto 611-0011, Japan

Full list of author information is available at the end of the article

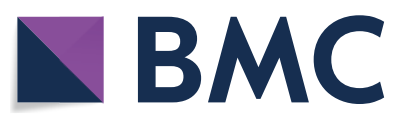

(c) The Author(s) 2020. This article is licensed under a Creative Commons Attribution 4.0 International License, which permits use, sharing, adaptation, distribution and reproduction in any medium or format, as long as you give appropriate credit to the original author(s) and the source, provide a link to the Creative Commons licence, and indicate if changes were made. The images or other third party material in this article are included in the article's Creative Commons licence, unless indicated otherwise in a credit line to the material. If material is not included in the article's Creative Commons licence and your intended use is not permitted by statutory regulation or exceeds the permitted use, you will need to obtain permission directly from the copyright holder. To view a copy of this licence, visit http://creativeco mmons.org/licenses/by/4.0/. The Creative Commons Public Domain Dedication waiver (http://creativecommons.org/publicdomain/ zero/1.0/) applies to the data made available in this article, unless otherwise stated in a credit line to the data. 
Keywords: Cellulase, Lignin, NMR, Carbohydrate-binding module, Cellobiohydrolase I, Enzyme adsorption, Chemical shift perturbation, HSQC, Lignin oligomer model

\section{Background}

The enzymatic saccharification of lignocellulose is a key process for the sustainable manufacture of green chemicals and biofuels [1]. Trichoderma reesei is a filamentous fungus widely used for producing commercially available cellulolytic enzyme cocktails. Cellobiohydrolase I (Cel7A) accounts for up to $60 \%$ of the cellulase secreted by $T$. reesei, and carbohydrate-binding module 1 ( $\operatorname{Tr} \mathrm{CBM} 1$ ) (Fig. 1) is connected to the C-terminal of the Cel7A catalytic domain by a highly glycosylated linker [3]. $\operatorname{TrCBM} 1$ enhances enzymatic activity by binding to cellulose $[4,5]$. $\operatorname{TrCBM} 1$ also has a strong affinity for lignin; hence, lignin significantly inhibits the enzymatic saccharification of pretreated lignocellulose [6, 7]. Thus, the nonproductive binding of $\operatorname{TrCBM} 1$ to lignin should be suppressed to achieve efficient enzymatic saccharification. However, the interaction mechanism is not entirely understood at the molecular level.

The binding of $\operatorname{TrCBM} 1$ to lignin is affected by various saccharification conditions, such as temperature $[8], \mathrm{pH}[9,10]$, and substrate concentration $[11,12]$. The chemical properties of lignin critically influence its cellulase-binding affinity. Many pretreatments increase the number of phenolic $\mathrm{OH}$ groups in lignin and its degree of condensation, which enhance the binding between cellulase and lignin [13, 14]. Electrostatic repulsion attributed to large numbers of aliphatic $\mathrm{OH}$ groups and negatively charged functionalities, such as carboxyl and sulfone groups, interferes with the cellulase binding [13, 15]. Softwood lignin is mainly synthesized by the radical coupling of guaiacyl monomers, whereas hardwood lignin is synthesized from both guaiacyl (G) and syringyl (S) monomers. The ratio of syringyl to guaiacyl units, denoted by $\mathrm{S} / \mathrm{G}$, is an important factor that governs the physicochemical properties of lignified plant cell walls.

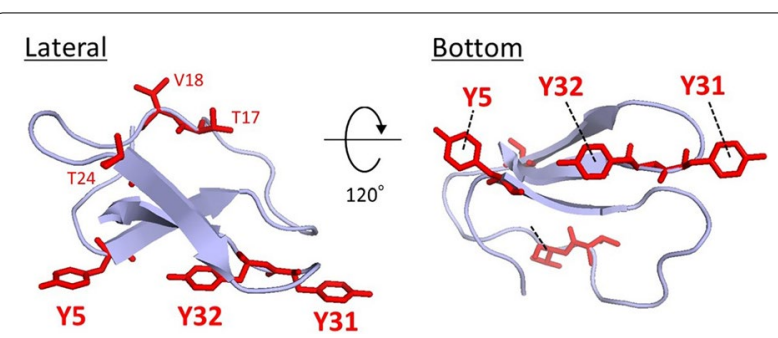

Fig. 1 Ribbon models of TrCBM1 viewed from the side and bottom. The structure of TrCBM1 was determined using the NMR analysis (PDB ID 2CBH) [2]. Red stick models of tyrosine residues (Y5, Y31, and Y32) and $T 17, V 18$, and $T 24$ residues in the cleft are also displayed
The $\mathrm{S} / \mathrm{G}$ ratio affects the nonproductive binding, but it is not the decisive factor for adsorption. Guo et al. found that a low S/G ratio corresponded to a high adsorption capacity [16]. Yang et al. reported that organosolv lignin isolated from softwood lodgepole pine exhibited a higher adsorption affinity for commercial cellulase than lignin from hardwood poplar [17]. However, genetic engineering studies have suggested the opposite, and comparisons of enzymatic hydrolysis in alfalfa cultivars and Eucalyptus mutants with high and low S/G ratios have yielded inconsistent results $[18,19]$. Although the relationship between the chemical structure of lignin and its binding affinity for cellulolytic enzymes and CBMs has been extensively researched, the evidence for identifying the binding atoms in whole lignin molecules is entirely lacking. This is because no effective method for identifying the interactive sites in lignin, a heterogeneous polymer, is available.

The NMR chemical shift perturbation (CSP) analysis is a powerful method for identifying substrate-binding sites in proteins [20, 21]. We previously performed CSP analysis to identify the binding amino acid residues in $\operatorname{TrCBM} 1$ with softwood and hardwood milled wood lignin (MWL) using ${ }^{15} \mathrm{~N}$-labeled $\operatorname{TrCBM1}$ [22]. The results suggested that the aromatic rings in the lignin participated in interactions with the amino acid residues in $\operatorname{TrCBM} 1$ because the flat plane surface, including Y5, Y31, and Y32 in $\operatorname{TrCBM} 1$, was the main interaction site. However, the binding sites in lignin have not been characterized at the molecular level.

Lignin is a heterogeneous polymer comprising $\mathrm{C} 6-\mathrm{C} 3$ phenylpropane units. These units are connected via different interunit bonding patterns; however, $\beta-O-4$ aryl ether is the dominant interunit linkage. Therefore, $\beta-O-4$ lignin oligomer models have been used to investigate the physicochemical properties and (bio)chemical reactivity of lignin [23, 24]. Recently, to analyze the conformational changes in the core lignin structure in solvents with different water contents, we synthesized lignin oligomer models composed of guaiacyl units interconnected solely via $\beta-O-4$ bonds with the erythro configuration [25]. In the present study, we focus on the analysis of the molecular interaction between $\operatorname{TrCBM} 1$ and the guaiacyl lignin model whose NMR signals were completely assigned [25]. To perform the CSP analysis of the binding sites with high sensitivity and distinctiveness, we labeled the $\beta$-O-4 lignin oligomer model compounds with ${ }^{13} \mathrm{C}$ at different positions. 
To monitor perturbations in the signals obtained from the binding sites in the model compounds, pure $\operatorname{TrCBM} 1$ without a catalytic domain and linker was expressed and purified and then added to NMR sample tubes containing the ${ }^{13} \mathrm{C}$-labeled lignin models. The NMR analysis of the ${ }^{13} \mathrm{C}$-labeled lignin model compounds provided the first direct evidence for identifying the binding atoms in the linear lignin chains. The results agreed well with our previous binding site analysis of the protein counterpart, $\operatorname{TrCBM} 1$ with MWL [22]. Herein, we provide direct evidence to reveal the interaction sites in the $\beta-O-4$ lignin substructure binding to $\operatorname{TrCBM} 1$.

\section{Results}

\section{Expression and purification of $\operatorname{TrCBM} 1$}

Escherichia coli BL21 (DE3) was used to express a histidine (His) tag-TrCBM1-green fluorescent protein (GFP) fusion protein. To obtain $\operatorname{TrCBM1}$, the His tag and GFP regions were removed by adding enterokinase and thrombin, respectively. In our previous research, to analyze the molecular mass and conformation of ${ }^{15} \mathrm{~N}$-labeled
$\operatorname{TrCBM1}$, we performed sodium dodecyl sulfate-polyacrylamide gel electrophoresis (SDS-PAGE), matrixassisted laser desorption/ionization time-of-flight mass spectrometry (MALDI-TOF-MS), and $2 \mathrm{D}{ }^{1} \mathrm{H}-{ }^{15} \mathrm{~N}$ heteronuclear single-quantum correlation (HSQC) NMR [22]. In this work, SDS-PAGE and MALDI-TOF-MS were performed to characterize unlabeled $\operatorname{TrCBM1}$. Pure $\operatorname{TrCBM} 1$ is a single protein with a molecular mass of $5195.8 \mathrm{Da}$. The MALDI-TOF-MS spectrum of TrCBM1 and a full-length SDS-PAGE gel are shown in Figure S1 of the Additional file 1.

\section{Synthesis and characterization of the lignin models}

Recently, we synthesized unlabeled $\beta$-O-4 lignin oligomer model compound 4 (Fig. 2); its NMR signals were completely assigned to all carbon atoms and nonexchangeable protons by conducting $1 \mathrm{D}^{1} \mathrm{H}$ NMR, $1 \mathrm{D}^{13} \mathrm{C}$ NMR, 2D ${ }^{1} \mathrm{H}-{ }^{13} \mathrm{C}$ HSQC, 2D ${ }^{1} \mathrm{H}-{ }^{13} \mathrm{C}$ heteronuclear multiple bond correlation (HMBC), and $2 \mathrm{D}{ }^{1} \mathrm{H}-{ }^{13} \mathrm{C}$ long-range heteronuclear single-quantum multiple bond correlation (LRHSQMBC) experiments [25]. We used the protocol to

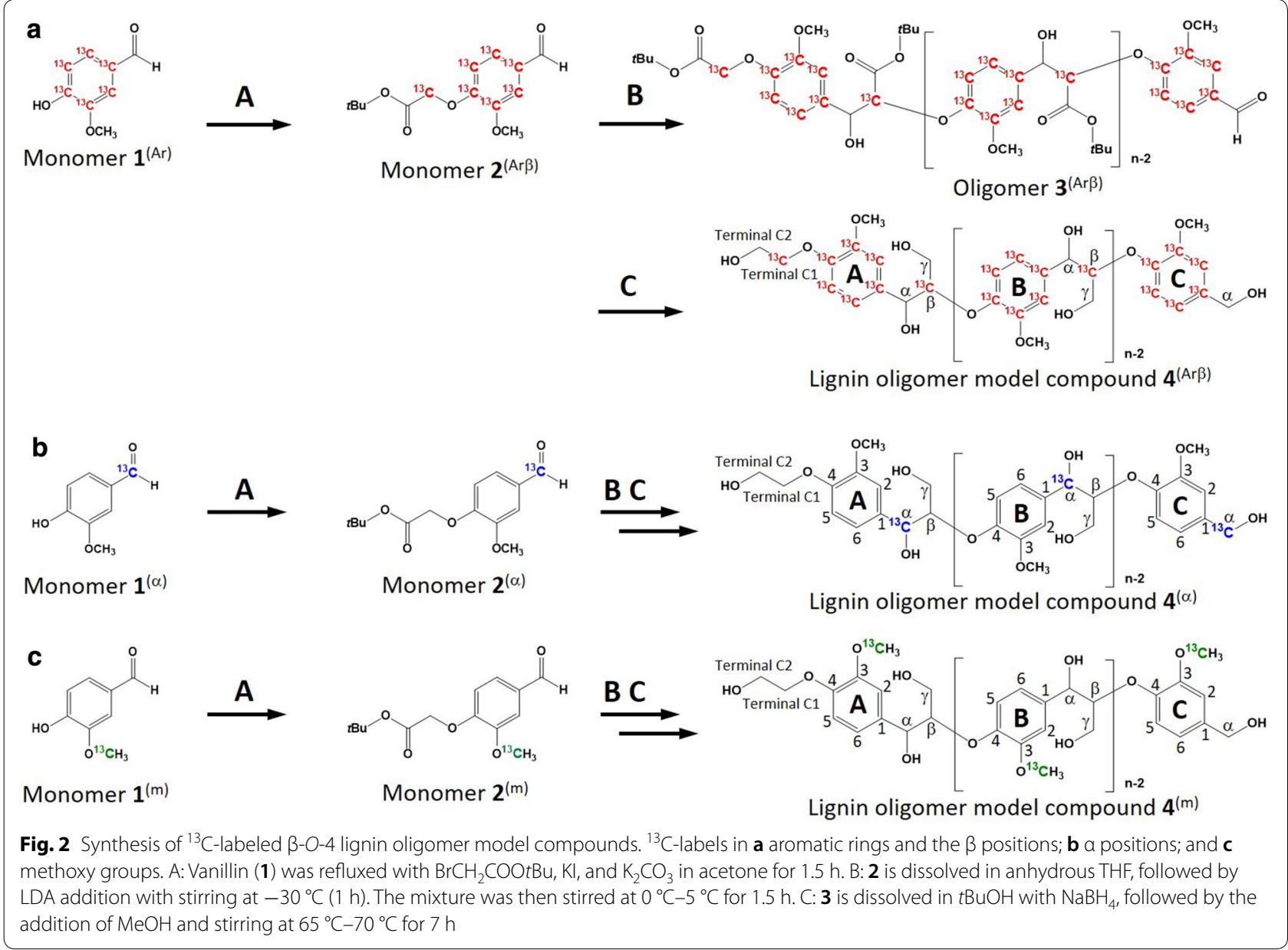


synthesize three ${ }^{13} \mathrm{C}$-labeled $\beta$-O-4 lignin oligomer model compounds. The ${ }^{13} \mathrm{C}$ labels were placed in the aromatic rings and $\beta$ positions of compound $4^{(\operatorname{Ar} \beta)}$, $\alpha$ positions of compound $\mathbf{4}^{(\alpha)}$, and methoxy groups of compound $\mathbf{4}^{(\mathrm{m})}$ using ${ }^{13} \mathrm{C}$-labeled vanillins and $t$-butyl-2-bromoacetate. The ${ }^{13} \mathrm{C}$-vanillins $\mathbf{1}^{(\operatorname{Ar} \beta)}, \mathbf{1}^{(\alpha)}$, and $\mathbf{1}^{(\mathrm{m})}$ were individually refluxed in acetone with unlabeled or ${ }^{13} \mathrm{C}$-labeled $t$-butyl-2-bromoacetate to afford ${ }^{13} \mathrm{C}$ - $t$-butoxycarbonylmethyl vanillins $2^{(\operatorname{Ar} \beta)}, \mathbf{2}^{(\alpha)}$, and $\mathbf{2}^{(\mathrm{m})}$, respectively. The ${ }^{13} \mathrm{C}$ - $t$-butoxycarbonylmethyl vanillins were dissolved in anhydrous tetrahydrofuran (THF) and polymerized using lithium diisopropylamide (LDA). The ester groups in polymerized ${ }^{13} \mathrm{C}$-oligomers $3^{(\mathrm{Ar} \beta)}, \mathbf{3}^{(\alpha)}$, and $\mathbf{3}^{(\mathrm{m})}$ were reduced using $\mathrm{NaBH}_{4}$ to obtain ${ }^{13} \mathrm{C}$-labeled $\beta-O-4$ lignin oligomer model compounds $\mathbf{4}^{(\mathrm{Ar} \beta)}, \mathbf{4}^{(\alpha)}$, and $\mathbf{4}^{(\mathrm{m})}$, respectively.

Figure 3 shows the $2 \mathrm{D}{ }^{1} \mathrm{H}-{ }^{13} \mathrm{C}$ HSQC spectra of the ${ }^{13} \mathrm{C}$-labeled lignin models. Recently, we reported the
HSQC spectra of the unlabeled lignin model [25]. A comparison of the HSQC spectra of the ${ }^{13} \mathrm{C}$-labeled and unlabeled lignin models indicated that the HSQC signal intensity was significantly enhanced by the incorporation of ${ }^{13} \mathrm{C}$, unequivocally demonstrating that ${ }^{13} \mathrm{C}$ was incorporated into the designated positions in the labeled model. No HSQC signals attributable to the side products were observed in the NMR spectra, suggesting the fabrication of high-purity lignin models. The HSQC signals at $\delta_{\mathrm{C}} / \delta_{\mathrm{H}} 85.9 / 4.52-4.64,72.6 / 4.06-4.08$, and 113.2-123.6/6.81-7.06 ppm in the HSQC spectra of lignin model $4^{(\mathrm{Ar} \beta)}$ with ${ }^{13} \mathrm{C}$ labeling in the $\beta$ positions and aromatic rings (Fig. 3a) were assigned to the $\beta$ positions, Terminal $\mathrm{C} 1$, and aromatic regions, respectively. The HSQC spectra of lignin model $\mathbf{4}^{(\alpha)}$ (Fig. 3b) contained three signals at $\delta_{\mathrm{C}} / \delta_{\mathrm{H}} 74.7-75.0 / 4.92-4.98,74.8-$ 75.0/4.72-4.76, and 66.2/4.43-4.49 ppm, corresponding to the $\alpha$ positions in the $\mathrm{A}, \mathrm{B}$, and $\mathrm{C}$ rings, respectively. A

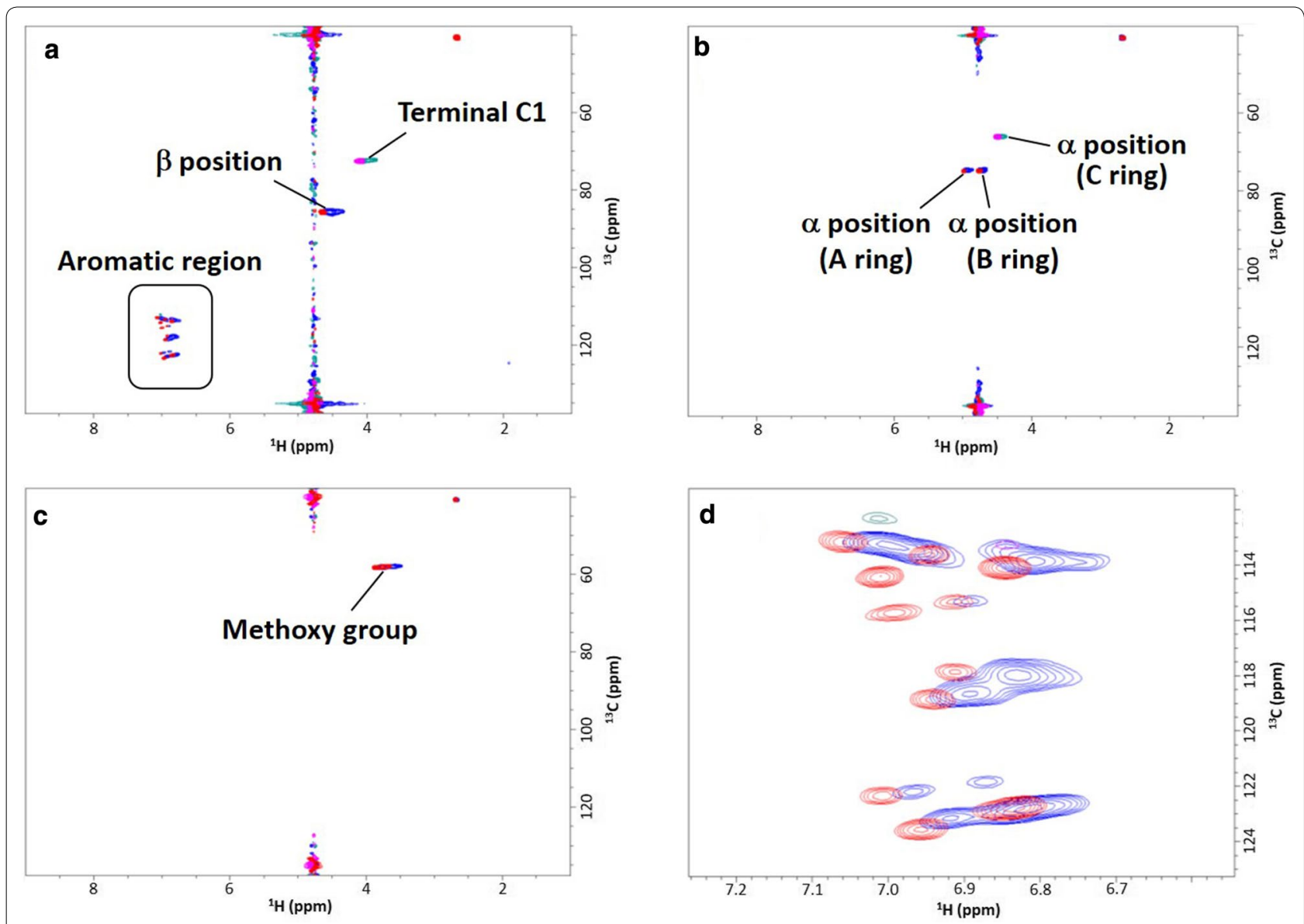

Fig. $32 \mathrm{D}^{1} \mathrm{H}-{ }^{13} \mathrm{C}$ HSQC spectra of ${ }^{13} \mathrm{C}$-labeled $\beta$-O-4 lignin oligomer model compounds. Superimposed $2 \mathrm{D}{ }^{1} \mathrm{H}-{ }^{13} \mathrm{C}$ HSQC spectra of the long-and short-chain models in $50 \mathrm{mM}$ acetic acid- $d_{4}$ buffer prepared using $\mathrm{D}_{2} \mathrm{O}(\mathrm{pD} 5.0)$ and $10 \%(\mathrm{v} / \mathrm{v}) \mathrm{DMSO}-d_{6}$ are shown in blue and red, respectively. 2D ${ }^{1} \mathrm{H}-{ }^{13} \mathrm{C}$ HSQC spectra of the lignin oligomer models with $\mathbf{a}{ }^{13} \mathrm{C}$-labeled aromatic rings and $\beta$ positions $\left(\mathbf{4}^{(\mathrm{A} \times \beta)}\right) ; \mathbf{b}^{13} \mathrm{C}$-labeled a positions $\left(\mathbf{4}^{(\alpha)}\right)$; and $\mathbf{c}$ ${ }^{13} \mathrm{C}$-labeled methoxy groups $\left(\mathbf{4}^{(\mathrm{m})}\right)$. $\mathbf{d}$ Magnified view of the aromatic region in (a). The noise observed in ${ }^{1} \mathrm{H}$-chemical shift of $4.75 \mathrm{corresponded}$ to the solvent residual peak of water 
single signal was observed at 58.1-58.3/3.57-3.85 ppm in the HSQC spectra of lignin model $4^{(\mathrm{m})}$ with ${ }^{13} \mathrm{C}$-labeled methoxy groups (Fig. 3c).

The long- and short-chain lignin models were separated via silica gel chromatography by sequential elution with (1) ethyl acetate, (2) ethyl acetate/methanol (5:1, $\mathrm{v} / \mathrm{v})$, and (3) ethyl acetate/methanol (2:1, v/v) for NMR and binding analyses. Size exclusion chromatography (SEC) revealed that the ${ }^{13} \mathrm{C}$-labeled lignin models exhibited narrow molecular weight distributions (Additional file 1: Figure S2). The degree of polymerization (DP) was calculated for each model compound based on its weightaverage molecular weight $(\mathrm{Mw})$. The DPs of the long- and short-chain lignin models ranged from 4.16 to 4.70 and from 2.64 to 3.12 , respectively (Table 1). Although differences between the Mws of the long- and short-chain models were small, their NMR spectra (Fig. 3d) and SEC profiles (Additional file 1: Figure S2) clearly differed. Therefore, the long- and short-chain lignin models could be used to evaluate the effects of $M \mathrm{w}$ on molecular interactions with $\operatorname{TrCBM1.}$

\section{Analysis of interactions between lignin models and TrCBM1}

The interactions between the lignin models and TrCBM1 were evaluated via CSP analysis using $2 \mathrm{D}{ }^{1} \mathrm{H}-{ }^{13} \mathrm{C}$ HSQC NMR. To observe the NMR signal perturbation with high clarity, the concentration of TrCBM1 should be several times higher than that of the lignin model. However, owing to experimental limitations for preparing a large amount of high-purity $\operatorname{Tr} C B M 1$, we used the ${ }^{13} \mathrm{C}$-labeled lignin model to decrease the concentration of the additive. The lignin models are composed of two terminal units (A and $\mathrm{C}$ rings) and internal units ( $\mathrm{B}$ rings), which are solely interlinked via the $\beta-O-4$ linkages with the erythro configuration. In the synthesized lignin model, only one alignment of the $\mathrm{A}$ and $\mathrm{B}$ rings was found, although the $\mathrm{C}$ ring exhibited two different alignments designated as $\mathrm{C}^{(\mathrm{I})}$ and $\mathrm{C}^{(\mathrm{II})}$ [25]. In $90 \% \mathrm{D}_{2} \mathrm{O}$, both configurations adopted the folded conformation; however, $\mathrm{C}^{(\mathrm{II})}$ had a slightly more compact conformation than $\mathrm{C}^{(\mathrm{I})}[25]$.

The 2D ${ }^{1} \mathrm{H}-{ }^{13} \mathrm{C}$ HSQC spectra of the lignin models $(50 \mu \mathrm{M})$ in the presence and absence of TrCBM1 were superimposed (Fig. 4). Several HSQC signals acquired in the presence of $200 \mu \mathrm{M}$ TrCBM1 showed obvious perturbation, particularly those in the aromatic regions in the long-chain lignin spectra. Most of these signals exhibited larger perturbations when the concentration of TrCBM1 was increased to $350 \mu \mathrm{M}$. The observed perturbations in the aromatic ring are shown in a close-up view (Fig. 4b), and these clear perturbations are good indicators of the interaction [26]. Conversely, the NMR signals obtained from the aliphatic regions and methoxy groups in the presence of TrCBM1 showed no significant perturbation (Fig. 4c). These results clearly indicated that the aromatic regions in the long-chain lignin models were the primary sites for interactions with $\operatorname{TrCBM} 1$. However, no distinct perturbations were observed in the signals acquired from the methoxy groups or any of the aromatic and aliphatic regions when the short-chain lignin models were used for CSP analysis (Additional file 1: Figures S3). This indicated that the length of the lignin chains was an important factor in $\operatorname{TrCBM} 1$ binding.

The change in the chemical shift $(\Delta \delta)$ of each signal was calculated by subtracting the chemical shift value in the spectrum of the lignin model from that of the model recorded in the presence of $\operatorname{TrCBM} 1$. The ${ }^{13} \mathrm{C}-$ ${ }^{13} \mathrm{C}$ coupling was not eliminated in the HSQC spectra. The CSP analysis was performed by tracing the center of the ${ }^{13} \mathrm{C}-{ }^{13} \mathrm{C}$ coupling signals with high accuracy because each signal was distinct in the HSQC spectra. The $\Delta \delta$ values obtained on the ${ }^{1} \mathrm{H}$ and ${ }^{13} \mathrm{C}$ axes are plotted in Fig. 5 . The $\Delta \delta$ values were large only for the signals obtained from the aromatic regions in the longchain lignin models, whereas those were small for the signals acquired from the aliphatic regions and methoxy groups in both the long- and short-chain lignin

Table 1 Molecular weight parameters of ${ }^{13} \mathrm{C}$-labeled and unlabeled $\beta$-0-4 lignin oligomer model compounds

\begin{tabular}{|c|c|c|c|c|c|}
\hline Lignin models & Chain length & $M_{n}$ & $M_{\mathrm{w}}$ & $M_{\mathrm{w}} / M_{\mathrm{n}}$ & $\mathrm{DP}^{\mathrm{a}}$ \\
\hline \multirow{2}{*}{$\begin{array}{l}\text { Compound } \mathbf{4}^{(\mathrm{Ar} \beta)}\left({ }^{13} \mathrm{C} \text {-labeled aromatic rings and } \beta \text { posi- }\right. \\
\text { tions) }\end{array}$} & Long & 843 & 923 & 1.095 & 4.70 \\
\hline & Short & 480 & 520 & 1.083 & 2.64 \\
\hline \multirow[t]{2}{*}{ Compound $\mathbf{4}^{(\mathrm{a})}\left({ }^{13} \mathrm{C}\right.$-labeled a positions $)$} & Long & 750 & 918 & 1.224 & 4.67 \\
\hline & Short & 531 & 614 & 1.156 & 3.12 \\
\hline \multirow[t]{2}{*}{ Compound $\mathbf{4}^{(\mathrm{m})}{ }^{13} \mathrm{C}$-labeled methoxy groups) } & Long & 629 & 818 & 1.301 & 4.16 \\
\hline & Short & 482 & 587 & 1.218 & 2.98 \\
\hline \multirow[t]{2}{*}{ Compound $\mathbf{4}$ (unlabeled) } & Long & 882 & 964 & 1.092 & 4.91 \\
\hline & Short & 552 & 560 & 1.014 & 2.85 \\
\hline
\end{tabular}

a DP Degree of polymerization calculated from the $M w$ and theoretical molecular mass of the lignin model 

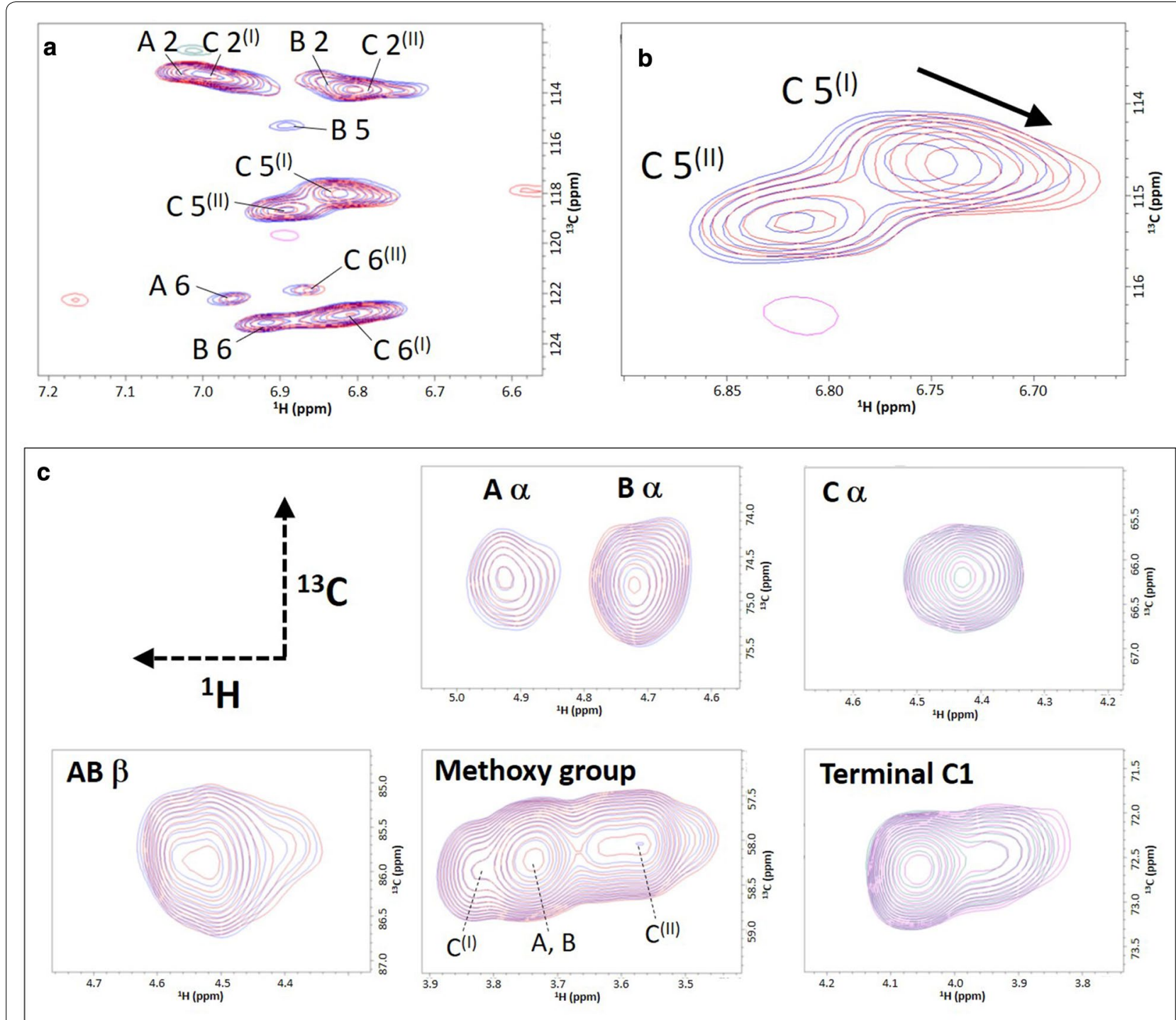

Fig. $42 \mathrm{D}{ }^{1} \mathrm{H}-{ }^{13} \mathrm{C} \mathrm{HSQC}$ spectra of the long-chain ${ }^{13} \mathrm{C}$-labeled lignin oligomer models in the CSP experiment. a Superimposed $2 \mathrm{D}{ }^{1} \mathrm{H}-{ }^{13} \mathrm{C} \mathrm{HSQC}$ spectra of the aromatic region in compound $\mathbf{4}^{(\mathrm{Ar} B)}(50 \mu \mathrm{M})$ in the presence (red) and absence (blue) of $350 \mu \mathrm{M} \operatorname{TrCBM1}$. b A magnified image of the HSQC signals from the $\mathrm{C} 5$ positions. c Superimposed $2 \mathrm{D}^{1} \mathrm{H}-{ }^{13} \mathrm{C} \mathrm{HSQC}$ spectra of aliphatic regions and methoxy groups in $\mathbf{4}^{(\mathrm{Ar} B)}, \mathbf{4}^{(\mathrm{a})}$, and $\mathbf{4}^{(\mathrm{m})}$ $(50 \mu \mathrm{M})$ in the presence (red) and absence (blue) of $350 \mu \mathrm{M} \operatorname{TrCBM} 1$

models. The $\Delta \delta$ values of the A $2, \mathrm{C} 2^{(\mathrm{I})}, \mathrm{B} 5, \mathrm{C} 5^{(\mathrm{I})}, \mathrm{C}$ $5^{(\mathrm{II})}, \mathrm{A} 6, \mathrm{C} 6^{(\mathrm{I})}$, and $\mathrm{C} 6^{(\mathrm{II})}$ signals obtained from the aromatic regions of the long-chain lignin models were all larger than $0.006 \mathrm{ppm}$ on the ${ }^{1} \mathrm{H}$ axis, whereas the $\Delta \delta$ values of the A 2 and $C 5^{(\mathrm{I})}$ signals on the ${ }^{13} \mathrm{C}$ axis were greater than $0.05 \mathrm{ppm}$ (Fig. 5a). For the shortchain lignin models, only the $\Delta \delta$ values of the B 5 signals on the ${ }^{1} \mathrm{H}$ axis exceeded 0.006 ppm (Fig. 5b). Line broadening was observed in the $\mathrm{B} 5$ signals of the long-chain lignin models in the presence of TrCBM1 $(350 \mu \mathrm{M})$. The observed line broadening could be attributed to both the on and off rates of the complex formation and multiple binding states of lignin due to nonspecific binding [22].

\section{Adsorption experiments with the lignin models}

The unlabeled long- and short-chain lignin models of compound 4 were used to evaluate $\operatorname{TrCBM} 1$ binding affinity based on the Langmuir adsorption model. The Mws and molecular weight distributions of the unlabeled lignin models (Table 1) were nearly identical to those of the ${ }^{13} \mathrm{C}$-labeled lignin models (Additional file 1: Figure S2). The $\operatorname{TrCBM1-His~tag~fusion~protein~was~}$ used instead of $\operatorname{TrCBM1}$ without a His tag to conduct 

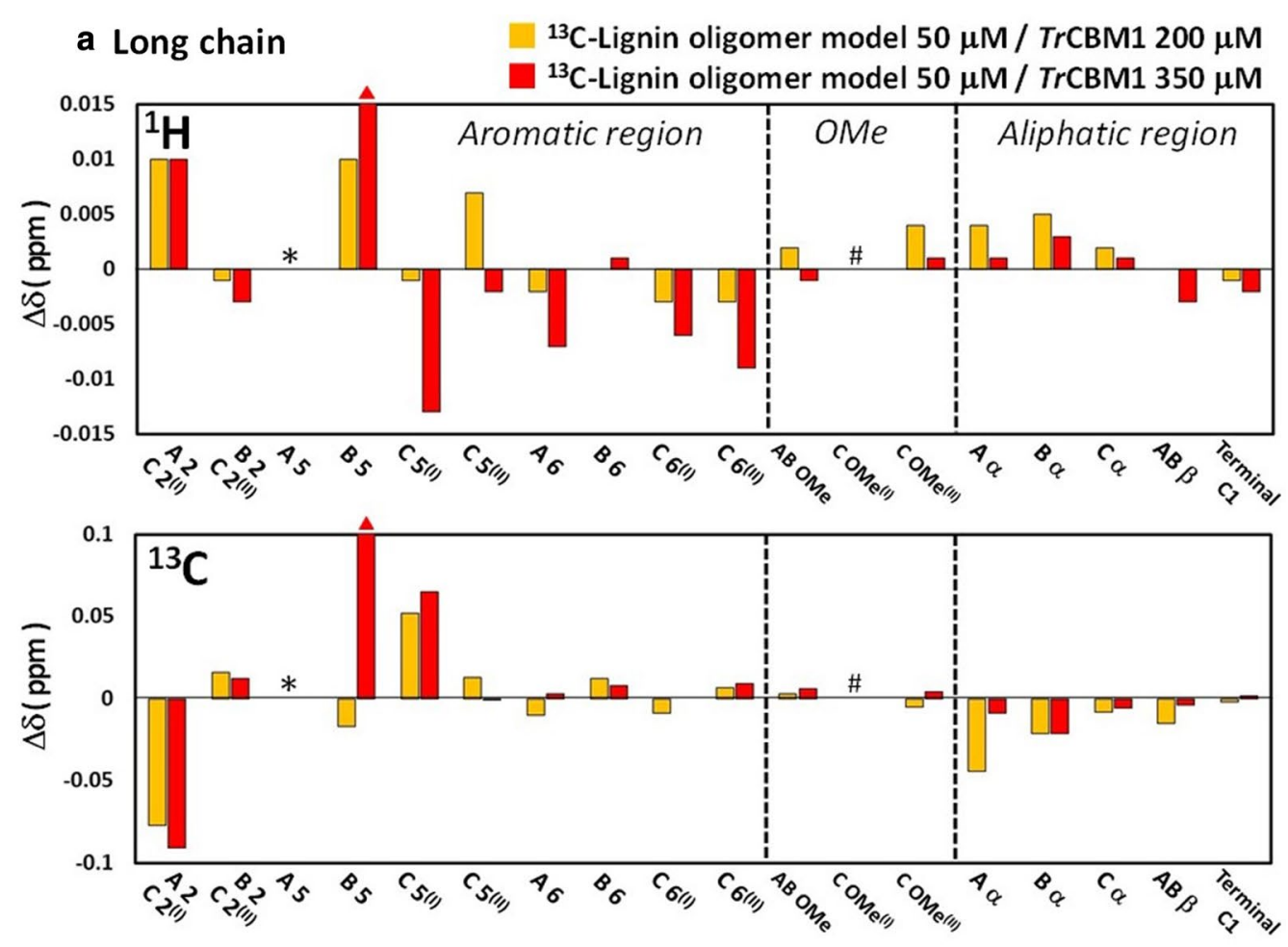

b Short chain $\quad{ }^{13} \mathrm{C}$-Lignin oligomer model $50 \mu \mathrm{M} / \operatorname{TrCBM1} 200 \mu \mathrm{M}$
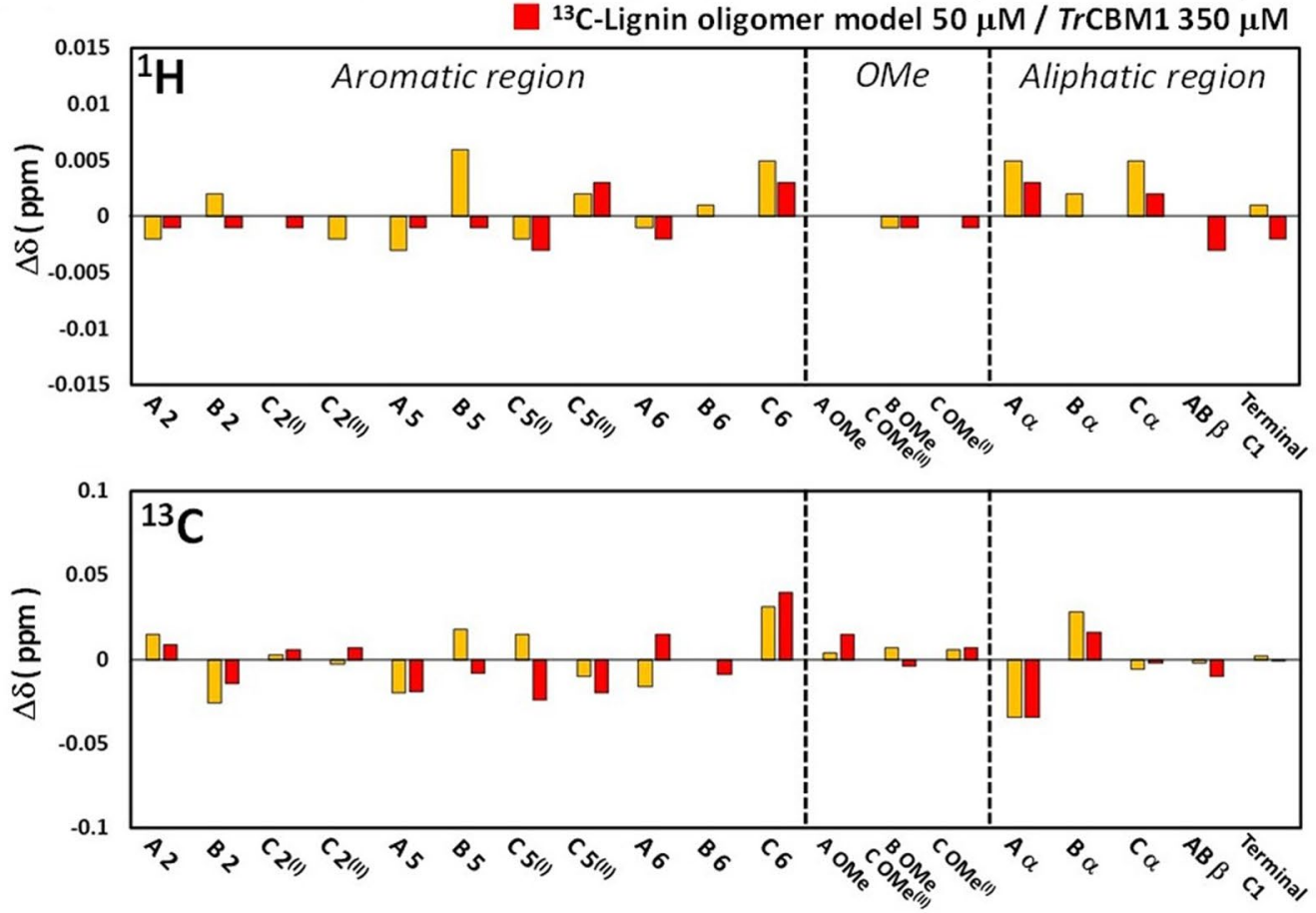

Fig. 5 Changes in the chemical shift $(\Delta \delta)$ observed in the CSP analysis. The CSP analysis of the ${ }^{13} \mathrm{C}$-labeled lignin oligomer models $(50 \mu M)$ was performed in the presence of 200 and $350 \mu \mathrm{M}$ of TrCBM1 in $50 \mathrm{mM}$ acetic acid- $d_{4}$ buffer prepared using $\mathrm{D}_{2} \mathrm{O}(\mathrm{pD} 5.0)$ and 10\% (v/v) DMSO- $d_{6}$. The $\Delta \delta$ values of signals from the $\mathbf{a}$ long- and $\mathbf{b}$ short-chain lignin oligomer models in the CSP experiment. The upper panels in $\mathbf{a}$ and $\mathbf{b}$ show $\Delta \delta$ on the ${ }^{1} \mathrm{H}$ axis. The lower panels show $\Delta \delta$ on the ${ }^{13} \mathrm{C}$ axis. Line broadening of the NMR signals from $\mathrm{B} 5$ in the long-chain lignin models was observed in the presence of $350 \mu \mathrm{M} \operatorname{TrCBM} 1$. Positions that generated extremely low-intensity signals in the absence of $\operatorname{TrCBM} 1$ are indicated by asterisks $(*)$. Positions that generated overlapping signals are indicated by \# symbols 
the adsorption experiments because the soluble lignin models could not be separated from the TrCBM1 protein via centrifugation. After incubating the sample solutions containing the lignin models and $\operatorname{TrCBM1-}$ His tag at $50{ }^{\circ} \mathrm{C}$ for $1 \mathrm{~h}$, cOmplete His-Tag Purification Resin (Roche, Basel, Switzerland) was added to the solutions. The unbound lignin models in the supernatant could then be separated from the bound lignin models, which were adsorbed on the precipitated $\operatorname{TrCBM} 1-\mathrm{His}$ tag that was bound to the His tag resin. By performing control experiments, we confirmed that all of the $\operatorname{TrCBM} 1-\mathrm{His}$ tag could adsorb onto the His tag resin. No undesired binding was observed between the His tag resin and lignin models (Additional file 1: Figures S6 and S7). To calculate the adsorption parameters summarized in Table 2, the concentrations of the unbound lignin models in the supernatants were determined. Although the long- and short-chain lignin models showed similar amount of the lignin model bound to His tag-TrCBM1 at saturation $\left(\Gamma_{\max }\right)$, the Langmuir affinity constant $\left(\mathrm{K}_{\mathrm{L}}\right)$ of the long-chain lignin model was eight times higher than that of the short-chain lignin model. This result was consistent with that of the NMR interaction analysis. The percentages of the lignin models that bound to TrCBM1 were calculated using the $\mathrm{K}_{\mathrm{L}}$ values. In the CSP analysis, $84.6 \%$ and $91.4 \%$ of the long-chain lignin models were bound to $\operatorname{TrCBM} 1$ at $\operatorname{TrCBM} 1$ concentrations of 200 and $350 \mu \mathrm{M}$, respectively. At $\operatorname{Tr} \mathrm{CBM} 1$ concentrations of 200 and $350 \mu \mathrm{M}, 33.0 \%$ and $46.6 \%$ of the short-chain lignin models, respectively, were bound to $\operatorname{Tr} C B M 1$. The chain length was, thus, an essential factor in the binding between $\operatorname{TrCBM} 1$ and the lignin chains, which exclusively contained $\beta-O-4$ linkages. We also found that a DP of greater than 4 was required for significant adsorption.

\section{Discussion}

Understanding the interaction mechanism between cellulase and lignin is essential for efficient enzymatic saccharification of lignocelluloses. T. reesei is the most important industrial cellulase-producing filamentous fungus. Cel7A is the most abundant secreted cellulolytic enzyme and contains a catalytic domain and $\operatorname{TrCBM} 1$. The nonproductive binding between $\operatorname{TrCBM} 1$

\begin{tabular}{|c|c|c|}
\hline Lignin model & $\begin{array}{l}\text { Langmuir affinity } \\
\text { constant, } \mathrm{K}_{\mathrm{L}}(\mathrm{mL} / \mathrm{mg})\end{array}$ & $\begin{array}{l}\text { Amount of adsorption } \\
\text { at saturation, } \Gamma_{\max }(\mu \mathrm{g} / \\
\mathrm{mg})\end{array}$ \\
\hline Long chain & 36.26 & 8.77 \\
\hline Short chain & 4.47 & 9.15 \\
\hline
\end{tabular}

and lignin decreases the efficiency of enzymatic saccharification of pretreated plant biomass; hence, the interaction mechanism has been previously studied. The flat plane surface of the $\operatorname{TrCBM} 1$ binds to both lignin and cellulose and contains three tyrosine residues (Y5, Y31, and Y32) and neighboring amino acid residues in the underside of $\operatorname{TrCBM} 1$ (Fig. 1) [9, 27, 28]. T17, V18, and T24 residues are present in the cleft, which is located on the opposite side of the flat plane surface. This site also interacts with lignin and cellulosic substrates [22]. Although the TrCBM1 binding sites have been extensively investigated using the point mutation analysis and NMR, the evidence to identify the lignin atoms participating in $\operatorname{TrCBM} 1$ binding is lacking. Therefore, we conducted the CSP analysis to investigate the interactions between ${ }^{13} \mathrm{C}$-labeled $\beta$-O-4 lignin oligomer compounds and $\operatorname{TrCBM} 1$.

Our CSP results clearly indicated that the long-chain lignin model showed a stronger affinity for $\operatorname{TrCBM} 1$ than the short-chain lignin model (Table 2). Mattinen et al. found that cellohexaose adsorbed on the TrCBM1, whereas short cellooligosaccharides, such as cellobiose and cellotriose, did not bind to TrCBM1 [29]. Based on these results and our observations, stacking on the flat plane surface of $\operatorname{TrCBM} 1$ and interactions with the cleft required lignin and cellooligosaccharides with long chains. The low affinity of the short-chain lignin model could also be attributed to its conformation. The shortchain lignin model adopted a folded conformation in $90 \%$ water [25], and the folded short lignin chain could not cover the full length of the three tyrosine residues on the flat plane surface of $\operatorname{TrCBM} 1$. Therefore, we surmise that the $\beta-O-4$ lignin chains with DPs above 4 were a prerequisite for the strong adsorption of $\operatorname{TrCBM} 1$.

The interactive sites in the long-chain lignin model are mapped in Fig. 6; these sites are based on the $\Delta \delta$ values observed in the CSP analysis. The interactions between the aromatic rings and $\operatorname{TrCBM} 1$ were obvious, whereas the aliphatic regions and methoxy groups did not exhibit major binding sites. This finding suggests that the adsorption of $\operatorname{TrCBM} 1$ on lignin occurs via hydrophobic interactions and $\pi-\pi$ stacking of the aromatic rings in lignin and three tyrosine residues on $\operatorname{TrCBM} 1$. Rahikainen et al. discussed the importance of $\operatorname{TrCBM} 1$ hydrophobicity. They reported that a Y32A $\operatorname{Tr}$ CBM1 mutant exhibited a lower association constant than the wild-type $\operatorname{Tr} \mathrm{CBM} 1$, whereas a Y32W mutant increased the lignin and cellulose binding affinities of $\operatorname{TrCBM} 1$ [9]. The hydrophobicity of lignin causes a significant amount of nonproductive binding with cellulase $[17,30]$. Therefore, the hydrophobic interaction can reasonably be interpreted as a dominant driving force behind nonproductive $\operatorname{TrCBM1}$ binding by lignin. 

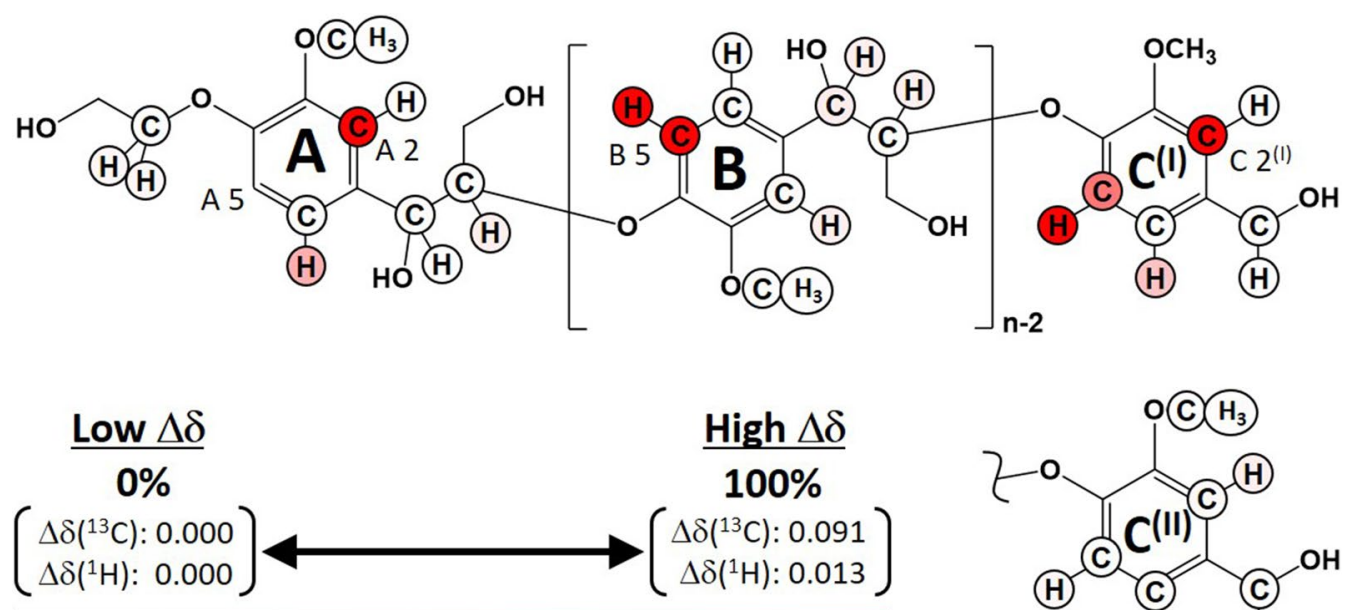

Fig. 6 Mapping of lignin model binding sites with $\operatorname{TrCBM1}$. The $\triangle \delta$ s observed in the CSP experiment using the long-chain lignin model with $350 \mu \mathrm{M}$ of $\operatorname{TrCBM} 1$ are shown by red gradation, which corresponds to the relative intensities of $\triangle \delta$ s. Differently aligned terminal units of two different configurations, $C^{(1)}$ and $C^{(I)}$, are exhibited. In the A 2 and $C 2^{(1)}$ positions, the $\Delta \delta$ value is the same because their 2D HSQC signals were not distinguishable due to overlapping

Interestingly, a variety of $\Delta \delta$ in the aromatic rings of the lignin model is observed (Fig. 6). The terminal units on the $\mathrm{A}$ and $\mathrm{C}^{(\mathrm{I})}$ rings exhibited similar interaction patterns, although the A 5 position was not evaluated due to its extremely weak HSQC signal intensity. The internal units, $\mathrm{B}$ ring, showed remarkable interactions with $\operatorname{TrCBM} 1$ only at the B 5 position, suggesting that the interaction patterns of the terminal and internal units of the lignin model differed. We previously reported two configurations of the lignin models whose terminal units were differently aligned and designated them $\mathrm{C}^{(\mathrm{I})}$ and $C^{(I I)}$ [25]. We demonstrated that the TrCBM1 binding behavior significantly depended on the lignin model configurations. The molecular alignment of $\mathrm{C}^{(\mathrm{I})}$ apparently resulted in preferential binding to $\operatorname{TrCBM} 1$. Thus, we are the first to reveal that the interactive sites in the lignin chains are significantly influenced by their molecular configurations.

Hydrogen bonding and electrostatic interactions are not negligible in nonproductive $\operatorname{TrCBM} 1$ binding. The phenolic $\mathrm{OH}$ groups in lignin promote hydrogen bonding to cellulolytic enzymes $[14,31]$. The hydrophilic amino acid residues in $\operatorname{TrCBM} 1$, including Q7 and T17 in addition to the main chain of $\mathrm{H} 4$ and I11, were previously shown to participate in binding with lignin via hydrogen bonds and electrostatic interactions [22]. In our CSP analysis, aromatic rings in the lignin models were the primary sites for interactions with $\operatorname{TrCBM1}$. This was mainly attributed to the hydrophobic interactions. However, the results could also be interpreted in terms of hydrogen $-\pi$ interactions between the aromatic rings in lignin and $\mathrm{OH}$ groups in the amino acid residues $[32,33]$. The $\mathrm{OH}$ groups in the three tyrosine residues on the flat plane surface of $\operatorname{TrCBM} 1$ and those in the T17 residue in the cleft were assumed to donate hydrogen for the hydrogen $-\pi$ interactions. Although the CSP analysis indicated that the interactions at the aliphatic positions were insignificant compared with those at the aromatic positions, the signals from the $\alpha$ positions exhibited slightly higher $\Delta \delta$ values than those from other aliphatic positions in the lignin models (Fig. 5). This result could be attributed to hydrogen binding between $\mathrm{OH}$ groups near the $\alpha$ positions of the lignin model and TrCBM1.

\section{Conclusions}

Highly efficient enzymatic saccharification is hindered by the nonproductive binding of lignin to cellulolytic enzymes. Until now, the binding mechanism was not fully understood. We synthesized ${ }^{13} \mathrm{C}$-labeled $\beta-O-4$ lignin oligomer model compounds to identify the TrCBM1 binding sites in lignin using the NMR CSP analysis. The signals from the aromatic regions in the lignin models exhibited obvious perturbations, whereas those from the aliphatic regions and methoxy groups were insignificantly perturbed. These results suggested that the aromatic rings in the lignin models are major sites for interactions with $\operatorname{TrCBM} 1$. $\operatorname{TrCBM} 1$ bound differently with the terminal and internal units in the lignin models. Moreover, the binding patterns associated with the $\mathrm{C}^{(\mathrm{I})}$ and $\mathrm{C}^{(\mathrm{II})}$ terminal alignments differed, indicating that the binding of the lignin models to TrCBM1 was strongly affected by the molecular configuration. The perturbation 
of the signals of the long-chain lignin models (DP 4.164.70) was obvious because of their strong binding affinity relative to that of the short-chain lignin models (DP 2.64-3.12). This finding indicated that a chain length greater than DP 4 was necessary for strong interactions between lignin and TrCBM1. In the complex between $\operatorname{TrCBM} 1$ and the long-chain lignin model, the aromatic rings of the lignin are core interactive sites for hydrophobic interactions and $\pi-\pi$ stacking with $\operatorname{TrCBM} 1$. A detailed understanding of the nonproductive binding will facilitate the establishment of a fundamental theory for the structural alteration of lignin and enzymes that are unsusceptible to unfavorable binding.

\section{Methods}

\section{Materials}

E. coli BL21 (DE3) was obtained from Merck (Darmstadt, Germany). Vanillins with the ${ }^{13} \mathrm{C}$-labeled carbonyl group and aromatic ring were obtained from Cambridge Isotope Laboratories (Tewksbury, MA, USA). Vanillin with the ${ }^{13} \mathrm{C}$-labeled methoxy group and $\left[2-{ }^{13} \mathrm{C}\right]-t$-butyl-2-bromoacetate were purchased from Taiyo Nippon Sanso (Tokyo, Japan). Other laboratory chemicals were obtained from Wako Pure Chemical Industries (Osaka, Japan), nacalai tesque (Kyoto, Japan), and Tokyo Chemical Industry (Tokyo, Japan).

\section{Preparation of $\operatorname{TrCBM} 1$}

The CBM1 of $T$. reesei Cel7A (accession number: CAH10320) was expressed and purified as described previously [22]. E. coli BL21 (DE3) was first subjected to heat shock transformation with plasmids for the expression of His-tagged $\operatorname{TrCBM} 1$ fused with GFP, hereafter referred to as His tag-TrCBM1-GFP fusion protein. The LB medium was inoculated with the transformant, followed by incubation at $37^{\circ} \mathrm{C}$ and $200 \mathrm{rpm}$ until the $\mathrm{OD}_{600}$ reached 1.2. Further, protein expression was induced using $1 \mathrm{mM}$ isopropyl $\beta$-1-thiogalactopyranoside, and the bacteria were incubated at $37{ }^{\circ} \mathrm{C}$ and $200 \mathrm{rpm}$ for $5 \mathrm{~h}$. Following centrifugation and sonication, the His tag-TrCBM1-GFP was isolated from the supernatant and purified by Ni affinity chromatography followed by anion exchange chromatography. The His tag and GFP regions were removed using enterokinase (New England Bio Labs, MA, USA) and thrombin (GE Healthcare, IL, USA), respectively. The obtained $\operatorname{TrCBM} 1$ was concentrated in $50 \mathrm{mM}$ acetic acid- $d_{4}$ buffer prepared with $\mathrm{D}_{2} \mathrm{O}$ using a Vivaspin turbo ultrafiltration device (Sartorius, Göttingen, Germany). We skipped the His tag cleavage process to prepare His tag-TrCBM1 for the adsorption analysis. The His tag-TrCBM1 was purified by Ni affinity and anion exchange chromatography.

\section{Synthesis of $\beta-0-4$ lignin oligomer model compounds}

The $\beta-O-4$ lignin oligomer models were synthesized as described in our previous work using a modified protocol originally developed by Katahira et al. [25, 34]. Vanillin (1) was dissolved in acetone, and the solution was refluxed for $1.5 \mathrm{~h}$ in the presence of $\mathrm{KI}, \mathrm{K}_{2} \mathrm{CO}_{3}$, and $t$-butyl-2-bromoacetate to obtain $t$-butoxycarbonylmethyl vanillin (2). The monomer (2) was dissolved in anhydrous THF, and 1.5 M LDA was added dropwise to the solution under nitrogen atmosphere over $30 \mathrm{~min}$ at a constant temperature of $-30^{\circ} \mathrm{C}$. The solution was stirred for $30 \mathrm{~min}$ at $-30{ }^{\circ} \mathrm{C}$ and for an additional $1.5 \mathrm{~h}$ at $0{ }^{\circ} \mathrm{C}-5{ }^{\circ} \mathrm{C}$ to obtain the polymerized oligomer (3). Oligomer 3 was dissolved in $t$-butanol containing $\mathrm{NaBH}_{4}$. Methanol was added to the mixture stepwise over $1 \mathrm{~h}$ under constant stirring at $65{ }^{\circ} \mathrm{C}-70{ }^{\circ} \mathrm{C}$, and the mixture was stirred for $6 \mathrm{~h}$ to obtain $\beta-O-4$ lignin oligomer model compound 4 . The synthesized lignin models were separated into longand short-chain fractions by silica gel chromatography. Sequential elution was performed using (1) ethyl acetate, (2) ethyl acetate/methanol (5:1, v/v), and (3) ethyl acetate/methanol $(2: 1, \mathrm{v} / \mathrm{v})$. Three types of the ${ }^{13} \mathrm{C}$-labeled lignin model compounds were synthesized for the CSP analysis. Vanillins with ${ }^{13} \mathrm{C}$-labeled aromatic rings $\left(\mathbf{1}^{(\mathrm{Ar})}\right)$ and $\left[2-{ }^{13} \mathrm{C}\right]-t$-butyl-2-bromoacetate were used as starting materials to synthesize a lignin model with ${ }^{13} \mathrm{C}$-labeled aromatic rings and $\beta$ positions $\left(\mathbf{4}^{(\mathrm{Ar} \beta)}\right)$. Similarly, vanillins with ${ }^{13} \mathrm{C}$-labeled carbonyl and methoxy groups were used to synthesize a lignin model with ${ }^{13} \mathrm{C}$-labeled $\alpha$ positions $\left(\mathbf{4}^{(\alpha)}\right)$ and a model with ${ }^{13} \mathrm{C}$-labeled methoxy groups $\left(4^{(m)}\right)$. The lignin models were characterized using 2D ${ }^{1} \mathrm{H}-{ }^{13} \mathrm{C}$ HSQC NMR and SEC. SEC was performed using three TSKgel SuperMultipore HZ-M columns (Tosho, Tokyo, Japan) on a Shimadzu instrument equipped with an LC-20AD pump and SPD-M20A diode array detector (Shimadzu, Kyoto, Japan). THF was used for elution at a flow rate of $0.35 \mathrm{~mL} / \mathrm{min}$ at $40{ }^{\circ} \mathrm{C}$.

\section{NMR spectroscopy and CSP analysis}

All NMR spectra were recorded at $298 \mathrm{~K}$ on a Bruker Avance III HD 600 spectrometer equipped with a cryogenic probe and $\mathrm{Z}$ gradient (Bruker BioSpin, MA, USA). The instrument was controlled using Bruker Topspin NMR software (version 3.5). For the CSP analysis, $50 \mu \mathrm{M}$ of the ${ }^{13} \mathrm{C}$-labeled lignin models with the ${ }^{13} \mathrm{C}$-labeled aromatic rings and $\beta$ positions $\left(\mathbf{4}^{(\operatorname{Ar} \beta)}\right)$, $\alpha$ positions $\left(4^{(\alpha)}\right)$, and methoxy groups $\left(4^{(\mathrm{m})}\right)$ were individually dissolved in $50 \mathrm{mM}$ acetic acid- $d_{4}$ buffer, which was prepared using $\mathrm{D}_{2} \mathrm{O}(\mathrm{pD} 5.0)$ and $10 \%(\mathrm{v} / \mathrm{v})$ DMSO- $d_{6}$. Each NMR sample comprised a volume of $250 \mu \mathrm{L}$ in a 5-mm Shigemi symmetrical microtube (Shigemi, Tokyo, Japan) and contained $20 \mu \mathrm{M}$ 
2,2-dimethyl-2-silapentane-5-sulfonic acid as an internal standard. To identify the $\operatorname{TrCBM} 1$ binding sites in the ${ }^{13} \mathrm{C}$-labeled lignin models, changes in the chemical shift $\left(\Delta \delta_{\mathrm{C}, \mathrm{H}}, \mathrm{ppm}\right)$ were calculated by comparing the chemical shift values in the edited ${ }^{1} \mathrm{H}-{ }^{13} \mathrm{C}$ HSQC spectra of the ${ }^{13} \mathrm{C}$-labeled lignin models in the presence and absence of 200 and $350 \mu \mathrm{M} \operatorname{TrCBM}$. The CSP analysis of both the long- and short-chain lignin models was performed to evaluate the effect of molecular weight on $\operatorname{TrCBM} 1$ binding to the lignin models. The assignment of the lignin model signals was based on our previous report [25]. All NMR experiments were performed in $90 \% \mathrm{D}_{2} \mathrm{O}$ because enzymatic saccharification is typically conducted in aqueous media, and the solubility of the lignin models was good in the NMR solvent owing to their low molecular weights.

\section{Adsorption experiment of lignin models with $\operatorname{TrCBM} 1$}

The Langmuir adsorption isotherm model was used to evaluate the $\operatorname{TrCBM} 1$ binding affinities of the lignin models. Each unlabeled long- and short-chain lignin model was dissolved in $50 \mathrm{mM}$ acetic acid buffer $(\mathrm{pH}$ 5.0) containing $3,200 \mu \mathrm{g} / \mathrm{mL}$ of $\operatorname{TrCBM} 1$ with a His tag (His tag-TrCBM1). The lignin models were prepared in 1.5-mL microtubes at concentrations of 10, 20, 30, 50, $80,100,150$, and $200 \mu \mathrm{M}$. The total volume of each solution was $50 \mu \mathrm{L}$. The sample solutions were incubated at $50{ }^{\circ} \mathrm{C}$ for $60 \mathrm{~min}$ under constant shaking at 1,000 rpm using a Comfort thermomixer (Eppendorf, Hamburg, Germany). To each solution, $100 \mu \mathrm{L}$ of a $50 \%$ (v/v) suspension of complete His-Tag Purification Resin (Roche, Basel, Switzerland) in the $50 \mathrm{mM}$ acetic acid buffer was added. The mixtures were resuspended by vortexing for $10 \mathrm{~s}$ and centrifuged at $500 \mathrm{~g}$ for $10 \mathrm{~s}$. The concentrations of the free lignin model in the supernatants were determined by measuring the absorbance at $280 \mathrm{~nm}$ using a BioSpec-nano spectrophotometer (Shimadzu, Kyoto, Japan). The quantity of each lignin model bound to $\operatorname{TrCBM1}$ was calculated by subtracting the amount of free lignin model compound from the initially loaded amount. Experiments were conducted in duplicate, and the average values were used to calculate the Langmuir affinity constants using Eq. (1)

$$
\Gamma_{C}=\Gamma_{\max }\left[K_{L} C /\left(1+K_{L} C\right)\right],
$$

where $\Gamma_{C}$ is the amount of the bound lignin model, $\Gamma_{\max }$ is the amount of the lignin model bound to His tag$\operatorname{TrCBM1}$ at saturation, $\mathrm{K}_{\mathrm{L}}$ is the Langmuir affinity constant, and $C$ is the concentration of the free lignin model in the supernatant. A solution containing only His tag$\operatorname{TrCBM1}$ without a lignin model was used as a blank.

\section{Supplementary information}

Supplementary information accompanies this paper at https://doi. org/10.1186/s13068-020-01805-w.

Additional file 1: Figure S1. TrCBM1 purity analysis using SDS-PAGE and MALDI-TOF-MS. Figure S2. Molecular weight distributions of the ${ }^{13} \mathrm{C}$-labeled and unlabeled $\mathrm{B}-\mathrm{O}-4$ lignin oligomer model compounds. Figure S3. 2D ${ }^{1} \mathrm{H}-{ }^{13} \mathrm{C}$ HSQC spectra of the short-chain ${ }^{13} \mathrm{C}$-labeled lignin oligomer models in the CSP experiment. Figure S4. Full $2 \mathrm{D}^{1} \mathrm{H}-{ }^{13} \mathrm{CHSQC}$ spectra from the CSP experiments. Figure S5. Full $2 \mathrm{D}^{1} \mathrm{H}-{ }^{13} \mathrm{C} \mathrm{HSQC}$ spectrum of $350 \mu \mathrm{M}$ TrCBM1. Figure S6. UV-vis spectra of the supernatant of the TrCBM1-His tag control used in the adsorption experiments. Figure S7. UV-vis spectra of the supernatants obtained in the adsorption experiments with the long- and short-chain models.

\section{Abbreviations}

CSP: Chemical shift perturbation; DMSO: Dimethyl sulfoxide; DP: Degree of polymerization; EXSY: Exchange spectroscopy; G: Guaiacyl; GFP: Green fluorescent protein; His tag: Histidine tag; HMBC: Heteronuclear multiple bond correlation; HSQC: Heteronuclear single-quantum correlation; LDA: Lithium diisopropylamide; LR-HSQMBC: Long-range heteronuclear single-quantum multiple bond correlation; MALDI-TOF-MS: Matrix-assisted laser desorption/ ionization time-of-flight mass spectrometry; Mw: Weight-average molecular weight; MWL: Milled wood lignin; NMR: Nuclear magnetic resonance; ROESY: Rotating-frame Overhauser effect spectroscopy; S: Syringyl; SDS-PAGE: Sodium dodecyl sulfate-polyacrylamide gel electrophoresis; SEC: Size exclusion chromatography; THF: Tetrahydrofuran; TOCSY: Total correlation spectroscopy.

\section{Acknowledgements}

We thank Dr. Isamu Katsuyama for supporting chemical synthesis of

${ }^{13} \mathrm{C}$-labeled lignin oligomer model compounds.

\section{Authors' contributions}

YT, TN, MK, TW designed the experiments. YT performed the experiments. YT, KK, TN analyzed and interpreted the NMR data. YT, TW, TN, MK wrote the paper. All authors read and approved the final manuscript.

\section{Funding}

This work was supported by JSPS KAKENHI Grant Number JP18J20331, a collaboration program of RISH (M2-2) and joint usage/research programs of IAE (ZE30A-36, ZE31A-37).

\section{Availability of data and materials}

All data generated or analyzed during this study are included in this manuscript and Additional files.

\section{Ethics approval and consent to participate}

Not applicable.

\section{Consent for publication}

Not applicable.

\section{Competing interests}

The authors declare that they have no competing interests.

\section{Author details}

${ }^{1}$ Research Institute for Sustainable Humanosphere (RISH), Kyoto University, Uji, Kyoto 611-0011, Japan. ${ }^{2}$ Institute of Advanced Energy (IAE), Kyoto University, Uji, Kyoto 611-0011, Japan.

Received: 24 June 2020 Accepted: 27 September 2020

Published online: 07 October 2020

\section{References}

1. Brunecky R, Subramanian V, Yarbrough JM, Donohoe BS, Vinzant TB, Vanderwall TA, Knott BC, Chaudhari YB, Bomble YJ, Himmel ME, Decker 
SR. Synthetic fungal multifunctional cellulases for enhanced biomass conversion. Green Chem. 2020;22:478-89.

2. Kraulis J, Clore GM, Nilges M, Jones TA, Pettersson G, Knowles J, Gronenborn AM. Determination of the three-dimensional solution structure of the C-terminal domain of cellobiohydrolase I from Trichoderma reesei. A study using nuclear magnetic resonance and hybrid distance geometrydynamical simulated annealing. Biochemistry. 1989;28:7241-57.

3. Seiboth B, Ivanova C, Seidl-Seiboth V. Trichoderma reesei: A fungal enzyme producer for cellulosic biofuels. In: Dos Santos Bernardes MA, editor. Biofuel Production-Recent Developments and Prospects. Rijeka: Intech; 2011. p. 309-40

4. Boraston AB, Bolam DN, Gilbert HJ, Davies GJ. Carbohydrate-binding modules: fine-tuning polysaccharide recognition. Biochem J. 2004;382:769-81.

5. Nidetzky B, Steiner W, Hayn M, Claeyssens M. Cellulose hydrolysis by the cellulases from Trichoderma reesei: a new model for synergistic interaction. Biochem J. 1994;298:705-10.

6. Palonen $\mathrm{H}$, Tjerneld F, Zacchi G, Tenkanen M. Adsorption of Trichoderma reesei $\mathrm{CBH}$ I and EG II and their catalytic domains on steam pretreated softwood and isolated lignin. J Biotechnol. 2004;107:65-72.

7. Rahikainen JL, Martin-Sampedro R, Heikkinen H, Rovio S, Marjamaa K, Tamminen T, Rojas OJ, Kruus K. Inhibitory effect of lignin during cellulose bioconversion: the effect of lignin chemistry on non-productive enzyme adsorption. Bioresour Technol. 2013;133:270-8.

8. Rahikainen JL, Moilanen U, Nurmi-Rantala S, Lappas A, Koivula A, Viikari $L$, Kruus K. Effect of temperature on lignin-derived inhibition studied with three structurally different cellobiohydrolases. Bioresour Technol. 2013;146:118-25.

9. Rahikainen JL, Evans JD, Mikander S, Kalliola A, Puranen T, Tamminen T, Marjamaa K, Kruus K. Cellulase-lignin interactions-the role of carbohydrate-binding module and $\mathrm{pH}$ in non-productive binding. Enzyme Microb Technol. 2013;53:315-21.

10. Lou H, Zhu JY, Lan TQ, Lai H, Qiu X. pH-Induced lignin surface modification to reduce nonspecific cellulase binding and enhance enzymatic saccharification of lignocelluloses. Chemsuschem. 2013;6:919-27.

11. Varnai A, Siika-Aho M, Viikari L. Carbohydrate-binding modules (CBMs) revisited: reduced amount of water counterbalances the need for CBMs. Biotechnol Biofuels. 2013:6:30

12. Pakarinen A, Haven MO, Djajadi DT, Varnai A, Puranen T, Viikari L. Cellulases without carbohydrate-binding modules in high consistency ethanol production process. Biotechnol Biofuels. 2014;7:27.

13. Yu Z, Gwak KS, Treasure T, Jameel H, Chang HM, Park S. Effect of lignin chemistry on the enzymatic hydrolysis of woody biomass. Chemsuschem. 2014;7:1942-50.

14. Huang $\mathrm{C}$, He J, Min D, Lai C, Yong Q. Understanding the nonproductive enzyme adsorption and physicochemical properties of residual lignins in moso bamboo pretreated with sulfuric acid and kraft pulping. Appl Biochem Biotechnol. 2016;180:1508-23.

15. Nakagame S, Chandra RP, Kadla JF, Saddler JN. Enhancing the enzymatic hydrolysis of lignocellulosic biomass by increasing the carboxylic acid content of the associated lignin. Biotechnol Bioeng. 2011;108:538-48.

16. Guo F, Shi W, Sun W, Li X, Wang F, Zhao J, Qu Y. Differences in the adsorption of enzymes onto lignins from diverse types of lignocellulosic biomass and the underlying mechanism. Biotechnol Biofuels. 2014;7:38.

17. Yang $Q$, Pan X. Correlation between lignin physicochemical properties and inhibition to enzymatic hydrolysis of cellulose. Biotechnol Bioeng. 2016;113:1213-24.

18. Dien BS, Miller DJ, Hector RE, Dixon RA, Chen F, McCaslin M, Reisen P, Sarath G, Cotta MA. Enhancing alfalfa conversion efficiencies for sugar recovery and ethanol production by altering lignin composition. Bioresour Technol. 2011;102:6479-86.
19. Papa G, Varanasi P, Sun L, Cheng G, Stavila V, Holmes B, Simmons BA, Adani F, Singh S. Exploring the effect of different plant lignin content and composition on ionic liquid pretreatment efficiency and enzymatic saccharification of Eucalyptus globulus L. mutants. Bioresour Technol. 2012;117:352-9.

20. Zuiderweg ERP. Mapping protein-protein interactions in solution by NMR Spectroscopy. Biochemistry. 2002;41:1-7.

21. Viegas A, Sardinha J, Freire F, Duarte DF, Carvalho AL, Fontes CM, Romao MJ, Macedo AL, Cabrita EJ. Solution structure, dynamics and binding studies of a family 11 carbohydrate-binding module from Clostridium thermocellum (CtCBM11). Biochem. J. 2013;451:289-300.

22. Tokunaga Y, Nagata T, Suetomi T, Oshiro S, Kondo K, Katahira M, Watanabe T. NMR analysis on molecular interaction of lignin with amino acid residues of carbohydrate-binding module from Trichoderma reesei Cel7A. Sci Rep. 2019;9:1977.

23. Lancefield CS, Ojo OS, Tran F, Westwood NJ. Isolation of functionalized phenolic monomers through selective oxidation and $\mathrm{C}-\mathrm{O}$ bond cleavage of the $\beta-O-4$ linkages in lignin. Angew Chem Int Ed. 2015;54:258-62.

24. Parsell TH, Owen BC, Klein I, Jarrell TM, Marcum CL, Haupert LJ, Amundson LM, Kenttämaa HI, Ribeiro F, Miller JT, Abu-Omar MM. Cleavage and hydrodeoxygenation (HDO) of $\mathrm{C}-\mathrm{O}$ bonds relevant to lignin conversion using Pd/Zn synergistic catalysis. Chem Sci. 2013:4:806-13.

25. Tokunaga Y, Nagata S, Kondo K, Katahira M, Watanabe T. Complete NMR assignment and analysis of molecular structural changes of $\beta-O-4$ lignin oligomer model compounds in organic media with different water content. Holzforschung, 74, in press (2020).

26. Liu YN, Lai YT, Chou WI, Chang MD, Lyu PC. Solution structure of family 21 carbohydrate-binding module from Rhizopus oryzae glucoamylase. Biochem J. 2007:403:21-30.

27. Linder M, Mattinen ML, Kontteli M, Lindeberg G, Stahlberg J, Drakenberg T, Reinikainen T, Pettersson G, Annila A. Identification of functionally important amino acids in the cellulose-binding domain of Trichoderma reesei cellobiohydrolase I. Protein Sci. 1995;4:1056-64.

28. Strobel KL, Pfeiffer KA, Blanch HW, Clark DS. Structural insights into the affinity of Cel7A carbohydrate-binding module for lignin. J Biol Chem. 2015;290:22818-26.

29. Mattinen ML, Linder M, Teleman A, Annila A. Interaction between cellohexaose and cellulose binding domains from Trichoderma reesei cellulases. FEBS Lett. 1997;407:291-6.

30. Ying W, Shi Z, Yang H, Xu G, Zheng Z, Yang J. Effect of alkaline lignin modification on cellulase-lignin interactions and enzymatic saccharification yield. Biotechnol Biofuels. 2018;11:214.

31. Sun S, Huang Y, Sun R, Tu M. The strong association of condensed phenolic moieties in isolated lignins with their inhibition of enzymatic hydrolysis. Green Chem. 2016;18:4276-86.

32. Suzuki S, Green PG, Bumgarner RE, Dasgupta S, Goddard WA 3rd, Blake GA. Benzene forms hydrogen bonds with water. Science. 1992;257:942-5.

33. Sipponen MH, Rahikainen J, Leskinen T, Pihlajaniemi V, Mattinen ML, Lange H, Crestini C, Osterberg M. Structural changes of lignin in biorefinery pretreatments and consequences to enzyme-lignin interactions. Nord Pulp Pap Res J. 2017;32:550-71.

34. Katahira R, Kamitakahara H, Takano T, Nakatsubo F. Synthesis of $\beta-O-4$ type oligomeric lignin model compound by the nucleophilic addition of carbanion to the aldehyde group. J Wood Sci. 2006;52:255-60.

\section{Publisher's Note}

Springer Nature remains neutral with regard to jurisdictional claims in published maps and institutional affiliations. 